\title{
Ruang Terbuka Hijau Dan Permasalahan Kesehatan Perkotaan Studi Kasus Di Provinsi Dki Jakarta
}

\author{
RAY MARCH SYAHADAT ${ }^{*}$, PRIAMBUDI TRIE PUTRA ${ }^{1}$, \\ MADE DWI PRATIWI2
}

1. Program Studi Arsitektur Lanskap, Fakultas Teknik Sipil dan Perencanaan, Institut Sains dan Teknologi Nasional

2. Program Studi Pendidikan Dokter, Fakultas Kedokteran, Universitas Tanjungpura

*E-mail: ray.arl@istn.ac.id

\section{ABSTRACT \\ Green Open Space and Urban Health Problem Case Study at Special Capital Region of Jakarta}

This article aims to describe the role of green open space from landscape architecture views. The research conducted in Special Capital Region of Jakarta as the case study in order to solve the health issue. Case study approach was used in this research, include the primary and secondary data from literature view and projection calculation. Green open space has important role to solve the urban health problem caused by the pollutant. The result of this study shows that in 2017 Jakarta needs approximately 291,592 ha of green open space. There was several options that can be used to raise the quality of public health with limited area: (1) the using of effective vegetation to reduce the pollutant; (2) utilization of home garden; (3) vertical greenery implementation; (4) utilization of indoor garden; and (5) maintain the existence of city parks.

Keywords: city park, indoor garden, polution, projection, vertical greenery.

\section{Pendahuluan}

Undang-undang Kesehatan No. 23 Tahun 1992 memberikan batasan mengenai konsep sehat. Kesehatan adalah keadaan sejahtera badan, jiwa, dan sosial yang memungkingkan setiap orang hidup produktif secara sosial dan ekonomi. Jadi, kesehatan itu mencakup empat aspek yakni fisik (badan), mental (jiwa), sosial, dan ekonomi. Keempat dimensi kesehatan tersebut saling memengaruhi dalam mewujudkan tingkat kesehatan pada seseorang, kelompok, atau masyarakat sebab kesehatan bersifat holistik dan menyeluruh.

Efendi et al. (2009) menyatakan bahwa kesehatan fisik yaitu jika seseorang tidak merasa sakit dan secara klinis memang tidak merasakan sakit serta tidak ada gangguan fungsi tubuh. Kesehatan sosial yakni jika seseorang mampu berhubungan dengan orang lain atau mampu berinteraksi dengan orang, kelompok lain tanpa membedakan ras, suku, 
agama, status sosial ekonomi, politik, serta saling menghargai dan toleransi. Kesehatan jiwa mencakup tiga komponen yaitu:

1. Pikiran yang sehat tercermin mampu berpikir logis.

2. Emosional yang tercermin dari kemampuan untuk mengekspresikan emosinya misalnya takut, gembira, khawatir, sedih, dan sebagainya.

3. Spiritual yang tercermin dari cara mengekspresikan rasa syukur yang dapat dilihat dari praktik keagaaman atau kepercayaannya, serta perbuatan baik yang sesuai dengan norma masyarakat.

Selanjutnya kesehatan aspek ekonomi yaitu kesehatan yang terlihat pada produktivitas seorang dewasa dalam arti mempunyai kegiatan yang menghasilkan sesuatu yang dapat menyokong hidupnya atau keluarganya secara finansial. Bagi anak, remaja, dan usia lanjut batasan ini tidak berlaku. Bagi kelompok tersebut produktif diartikan mempunyai kegiatan yang berguna bagi kehidupan mereka seperti sekolah, kuliah, dan kegiatan pelayanan keagamaan bagi usia lanjut.

McHarg (1971) menyebutkan pada kasus di perkotaan, orang miskin terkonsentrasi di daerah yang relatif kecil mengelilingi pusat komersial. Daerah ini relatif ada pada kota berpenyakit, namun tidak bisa mengklaim bahwa kemiskinan (ekonomi) adalah penjelasan mengenai adanya penyakit fisik, sosial dan mental. Kesehatan di perkotaan umumnya akibat kepadatan penduduk. Kepadatan penduduk yang tidak terkontrol menimbulkan sprawl sehingga menimbulkan dampak pada beberapa penyakit seperti stres. Peningkatan kepadatan juga berkorelasi terhadap tekanan sosial, yang juga menambah resiko munculnya penyakit jantung dan ginjal. Panjaitan et al. (2011) menambahkan, permasalahan kesehatan lainnya yang juga timbul akibat pencemaran udara yakni gangguan pernapasan, iritasi, dan bahkan kanker.

Arsitektur lanskap sebagai salah satu ilmu penataan dan pengelolaan lingkungan juga memiliki peran dalam menanggulangi masalah tersebut. Keberadaan ruang terbuka hijau (RTH) di perkotaan dapat menjadi salah satu solusi untuk mereduksi permasalahan kesehatan di perkotaan. Artikel ini bertujuan untuk menggambarkan peran RTH dalam sudut pandang arsitektur lanskap dalam menyelesaikan masalah kesehatan perkotaan dengan mengambil studi kasus di Provinsi DKI Jakarta.

\section{Metode}

Studi dilakukan di Provinsi DKI Jakarta pada tahun 2013. Metode yang digunakan menggunakan pendekatan studi kasus. Studi kasus yaitu sebuah metode deskriptif kualitatif dengan memusatkan diri secara intensif pada suatu permasalahan yang dianggap sebuah kasus. Data yang digunakan dalam artikel ini merupakan data primer maupun sekunder yang diperoleh dari studi literatur dan perhitungan proyeksi. Untuk melihat proyeksi kebutuhan RTH yang idealnya dibutuhkan oleh Jakarta maka dilakukan perhitungan dengan metode Gerarkis yang dimodifikasi dengan formula sebagai berikut:

$$
\mathrm{Lt}=((\mathrm{Pt}+\mathrm{Kt}) /(54 \times 0,9375)) \mathrm{m}^{2}
$$


Keterangan:

$\begin{array}{ll}\mathrm{Lt} & =\text { Luas RTH pada tahun } \mathrm{t}\left(\mathrm{m}^{2}\right) \\ \mathrm{Pt} & =\text { Jumlah Kebutuhan oksigen penduduk per hari pada tahun } \mathrm{t}(\mathrm{g} / \mathrm{hari}) \\ \mathrm{Kt} & =\text { Jumlah kebutuhan oksigen kendaraan bermotor perhari pada tahun } \mathrm{t} \\ & (\mathrm{g} / \mathrm{hari}) \\ = & \text { Konstanta, } 1 \mathrm{~m}^{2} \text { luas lahan menghasilkan } 54 \mathrm{~g} \text { berat kering tanaman } \\ 54 & \text { per hari }\left(\mathrm{g} / \mathrm{har} / \mathrm{m}^{2}\right) \\ = & \text { Konstanta, } 1 \mathrm{gram} \text { berat kering tanaman setara dengan produksi } \\ 0,9375 \quad & \text { oksigen } 0,9375 \mathrm{gram} \text { (g/hari) }\end{array}$

Proyeksi kebutuhan oksigen menggunakan formula sebagai berikut:

$$
\text { Kp = Jumlah Penduduk (jiwa) x 0,864 (kg/hari) }
$$

Keterangan:

$\mathrm{Kp}=$ Kebutuhan $\mathrm{O}_{2}$

$0,864=$ Oksigen yang dibutuhkan per hari

Proyeksi kebutuhan oksigen kendaraan menggunakan formula yang digunakan oleh Muis (2005) sebagai berikut:

$$
\mathrm{Ko}=\mathrm{KBB} \times \mathrm{Dk} \times \text { (kebutuhan } \mathrm{O}_{2} / 1 \mathrm{~kg} \text { bahan bakar) }
$$

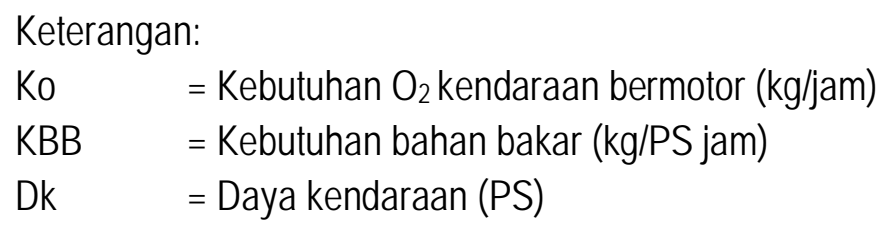

Adapun standar yang digunakan untuk menghitung kebutuhan oksigen masing-masing jenis kendaraan dapat dilihat pada Tabel 1.

Tabel 1. Kebutuhan oksigen berdasarkan jenis kendaraan bermotor

\begin{tabular}{lccc}
\hline $\begin{array}{l}\text { Jenis } \\
\text { kendaraan }\end{array}$ & $\begin{array}{c}\text { Kebutuhan Bahan Bakar } \\
(\mathrm{kg} / \mathrm{PS} \text { jam })\end{array}$ & $\begin{array}{c}\text { Daya Kendaraan } \\
(\mathrm{PS})\end{array}$ & $\begin{array}{c}\text { Kebutuhan } \mathrm{O}_{2} 1 \mathrm{~kg} \text { bahan bakar } \\
(\mathrm{kg})\end{array}$ \\
\hline Mobil & 0,21 & 20 & 2,77 \\
Motor & 0,21 & 1 & 2,77 \\
Bus & 0,16 & 100 & 2,77 \\
Truk & 0,16 & 50 & 2,86 \\
\hline
\end{tabular}

Sumber: Muis (2005)

Proyeksi jumlah penduduk setiap lima tahun menggunakan formula sebagai berikut:

$$
P t=P 2006 \times(1+0,05)^{t}
$$




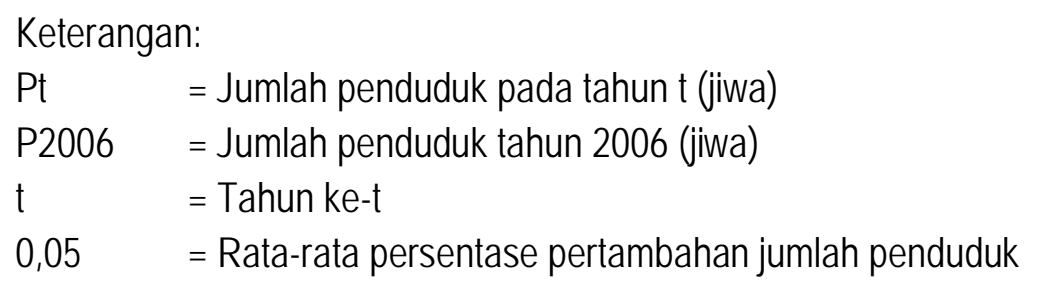

Proyeksi jumlah kendaraan setiap lima tahun menggunakan formula sebagai berikut:

$$
K t=K 2006 \times(1+0,095)^{t}
$$

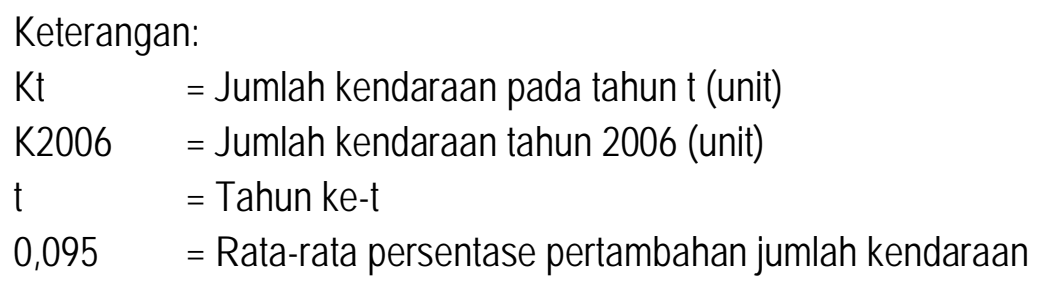

\section{Hasil dan Pembahasan}

Sebagai ibukota Republik Indonesia, Jakarta memiliki permasalahan udara yang tidaklah kecil. Bahkan biaya kesehatan yang dikeluarkan warga Jakarta dari tahun ke tahun kian membengkak. Salah satu penyebabnya ialah kualitas udara ibu kota yang kian buruk akibat pencemaran udara. Data tahun 2010 dilaporkan bahwa sebesar 38 triliun rupiah harus dikeluarkan oleh warga Jakarta untuk biaya pengobatan (Sasmita dan Ucu, 2012). Penyakit seperti asma, bronkitis, infeksi pernapasan, pneumonia, hingga jantung koroner merupakan salah satu contoh penyakit yang disebabkan pencemaran udara. Hal tersebut dikuatkan oleh kajian yang dilakukan oleh Segalowitz (2008), Genc et al. (2011), Liu et al. (2016a), dan Liu et al. (2016b) bahwa kualitas udara yang buruk meningkatkan jumlah penderita penyakit perrnapasan, sistem saraf, penyakit parkinson, serta kesehatan otak.

Studi yang dilakukan Komite Penghapusan Bensin Bertimbal atau yang dikenal dengan KPBB, menunjukkan parameter pencemaran udara pada 2011-2012 menembus angka $60 \mu \mathrm{g} / \mathrm{m}^{3}$. Apabila mengacu pada standar nasional, parameter pencemaran udara seharusnya sebesar $50 \mu \mathrm{g} / \mathrm{m}^{3}$. Standar World Health Organization (WHO) lebih rendah lagi yaitu sebesar $20 \mu \mathrm{g} / \mathrm{m}^{3}$. Parameter lainnya adalah tingkat pencemaran nitrogen dioksida dan oksigen, yang menyebabkan beberapa penyakit. Adapun penyakit-penyakit tersebut seperti kerusakan pada sistem saraf, gangguan fungsi ginjal, bahkan penurunan kemampuan intelektual pada anak-anak (Sunyer et al., 2015). Pencemaran udara juga mengakibatkan impotensi, keguguran, jantung koroner, kanker, serta kematian dini (Sasmita dan Ucu, 2012; Hoek et al., 2013; Liu et al., 2016; Lin et al., 2017).

Dari sisi kesehatan mental, data Departemen Kesehatan bahkan menyebut jumlah pasien gangguan jiwa di DKI Jakarta adalah yang terbanyak. Mencapai 2,03 persen dari jumlah penduduk di Indonesia. Data ini berdasar hasil riset yang dilakukan Departemen 
Kesehatan pada 2007 silam selama setahun. Banyak faktor yang mengakibatkan angka penderita gangguan jiwa di Jakarta sangat tinggi. Padatnya aktivitas kerja, kurang istirahat, kurang olahraga, lupa makan karena berbagai kesibukan, tingkat polusi, macet, banjir, dan buruknya fasilitas publik seolah menjadi senyawa solid penyebab stres (Noorastuti dan Kurniawan, 2009). Berdasarkan data Riskesdas tahun 2014, beban penyakit mental di Indonesia cukup tinggi dengan penjabaran sekitar 1 juta pasien gangguan jiwa berat dan 19 juta pasien gangguan jiwa ringan (Intelresos, 2017). Data BPS 2009 memprediksi di Jakarta masih ada sekitar 1.300 orang warga mengalami gangguan jiwa. Mereka dari keluarga miskin dan telah mendapat pelayanan di panti sosial (Parjiyono, 2010). WHO pada tahun 1990 melaporkan dari sepuluh masalah kesehatan utama yang menyebabkan disabilitas, lima di antaranya merupakan masalah kesehatan jiwa. Prediksi WHO pada tahun 2020, depresi akan menjadi penyakit urutan kedua dalam menimbulkan beban kesehatan (Intelresos, 2017).

Hubungan profesi arsitektur lanskap dan masalah kesehatan di perkotaan dapat dilihat dari peran arsitektur lanskap dalam menata RTH di perkotaan. Joga dan Ismaun (2011) menyatakan tujuan pembangunan RTH sebagai infrastruktur hijau di wilayah perkotaan adalah meningkatkan kualitas lingkungan hidup perkotaan yang nyaman, segar, indah, dan bersih, sebagai sarana lingkungan perkotaan; menciptakan keserasian lingkungan alami dan lingkungan binaan yang berguna untuk kepentingan masyarakat; dan menciptakan kota yang sehat, layak huni, dan berkelanjutan (liveable, habitable, and sustainable).

Permasalahan yang timbul dari RTH di Jakarta yaitu tingginya jumlah penduduk dan kondisi ruang Jakarta (data tahun 2009) terdiri atas ruang terbangun 67\%, RTH 10\% (tepatnya 9,97\%), dan menyisakan lahan yang tengah diperebutkan untuk menjadi RTH atau kawasan komersial sebesar 23\% (Joga dan Ismaun, 2011). RTH sangat dibutuhkan di Jakarta sebab RTH memiliki fungsi bukan hanya untuk kenyaman termal, estetika, dan tempat hidup makhluk hidup lainnya tapi juga dapat mereduksi polutan yang mengganggu kesehatan manusia.

Tabel 2 menunjukkan proyeksi kebutuhan $\mathrm{O}_{2}$ (kg/hari) pada setiap kategori kendaraan bermotor. Selanjutnya, Tabel 3 menunjukkan luas kebutuhan RTH pada tahun 2007, 2012, dan 2017 yang direkomendasikan berdasarkan perhitungan metode Gerarkis. Dengan bertambahnya jumlah penduduk, maka kebutuhan oksigen juga meningkat. Adanya penambahan jumlah kendaraan, dapat mempengaruhi jumlah oksigen yang dibutuhkan. Selanjutnya, seperti yang kita ketahui oksigen diproduksi dari hasil fotosintesis tanaman sehingga untuk meningkatkan oksigen perlu adanya RTH di perkotaan. Berdasarkan hasil proyeksi kebutuhan RTH, kebutuhan luas RTH Jakarta dari tahun ke tahun harus bertambah. Proyeksi kebutuhan tahun 2017 RTH Jakarta diperlukan hampir tiga juta meter persegi. Pada proyeksi ini kebutuhan oksigen hewan ternak diasumsikan nol mengingat Jakarta merupakan kota jasa dengan variabel perternakan yang sangat kecil dibandingkan dengan manusia dan kendaraan bermotor. 
Tabel 2. Proyeksi kebutuhan $\mathrm{O}_{2}$ (kg/hari) pada setiap kategori kendaraan bermotor

\begin{tabular}{|c|c|c|c|c|c|c|c|}
\hline \multirow[t]{2}{*}{ Jenis } & \multirow{2}{*}{$\begin{array}{c}\text { Kebutuhan } \\
\mathrm{O}_{2} \\
\text { (kg/hari) }\end{array}$} & \multicolumn{3}{|c|}{$\begin{array}{l}\text { Jumlah Kendaraan } \\
\text { (unit) }\end{array}$} & \multicolumn{3}{|c|}{$\begin{array}{l}\text { Kebutuhan } \mathrm{O}_{2} \\
\text { (kg/hari) }\end{array}$} \\
\hline & & 2007 & 2012 & 2017 & 2007 & 2012 & 2017 \\
\hline $\begin{array}{l}\text { Mobil } \\
\text { pribadi }\end{array}$ & 11,63 & 1.989 .288 & 2.859 .992 & 4.502 .201 & 23.135 .419 & 33.261 .706 & 52.360 .597 \\
\hline $\begin{array}{l}\text { Sepeda } \\
\text { motor }\end{array}$ & 0,58 & 5.624 .597 & 8.086 .264 & 12.729 .711 & 3.262 .266 & 4.690 .033 & 7.383 .232 \\
\hline Bus & 44,32 & 551.595 & 793.007 & 1.248 .382 & 24.446 .690 & 35.146 .070 & 55.328 .290 \\
\hline Truk & 22,88 & 347.001 & 498.869 & 785.340 & 7.939 .382 & 11.374 .213 & 17.968 .579 \\
\hline Jumlah & & 8.512 .481 & 12.238 .064 & 19.265 .420 & 58.783 .757 & 84.472 .022 & 133.040 .698 \\
\hline
\end{tabular}

Sayangnya, jumlah ruang terbuka hijau di Jakarta tidak menunjukkan tren yang meningkat. Pertumbuhan penduduk dan gencarnya arus permbangunan meningkatkan konversi lahan dari area hijau menjadi area terbangun. Untuk itu diperlukan beberapa strategi dalam pengelolaan area perkotaan. Persoalan lahan adalah hal yang sulit untuk meningkatkan luasan RTH secara kuantitatif. Untuk itu perlu diterapkan beberapa strategi untuk meningkatkan kualitas RTH demi menunjang kesehatan manusia baik dari sisi mereduksi polutan maupun mengurangi tingkat stres masyarakat. Penggunaan vegetasi yang efektif menyerap polutan merupakan salah satu strategi yang direkomendasikan. Penelitian yang dilakukan Nasrullah et al. (2000) menemukan beberapa tanaman yang efektif menyerap polutan $\mathrm{NO}_{2}$ yang tersaji pada Tabel 4 .

Tabel 3. Proyeksi luas kebutuhan RTH pada tahun 2007, 2012, dan 2017

\begin{tabular}{|c|c|c|c|}
\hline Variabel & 2007 & 2012 & 2017 \\
\hline Pt & 9.397.201 (g/hari) & 11.422 .357 (g/hari) & 14.578.144 (g/hari) \\
\hline $\mathrm{Kt}$ & 58.783 .757 (g/hari) & 84.472 .022 (g/hari) & 133.040.698 (g/hari) \\
\hline $\mathrm{Pt}+\mathrm{Kt}$ & 68.180 .958 (g/hari) & 95.894 .379 (g/hari) & 147.618.842 (g/hari) \\
\hline $\mathrm{Lt}$ & $1.346 .784,386 \mathrm{~m}^{2}$ & 1.894.209,956 m (m²) & $2.915 .927,743\left(\mathrm{~m}^{2}\right)$ \\
\hline
\end{tabular}

Tabel 4. Tanaman pohon dan semak yang efektif menyerap polutan $\mathrm{NO}_{2}$

\begin{tabular}{ll}
\hline \multicolumn{1}{c}{ Pohon } & \multicolumn{1}{c}{ Semak } \\
\hline Dadap kuning (Ertytrina variegata) & Jacobina (Jacobina carnea) \\
Kenanga (Canangium odoratum) & Kihujan (Malphigia sp) \\
Mlinjo (Gnetum gnemon) & Akalipa merah (Acalypha wilkesiana) \\
Kaliandra (Calliandra surinamensis) & Lolipop kuning (Pachistacis lutea) \\
Flamboyan (Delonix regia) & Nusa indah merah (Mussaendah filifica) \\
Kembang merak (Caesalpinia pulcerhima) & Bogenvil ungu (Bouganvillea spectabilis) \\
Asam kranji (Diallium indum) & Kaca piring (Gardenia augusta) \\
Kapuk (Ceiba pentandra) & Koleus (Coleus blumei)
\end{tabular}




\begin{tabular}{ll}
\hline \multicolumn{1}{c}{ Pohon } & \multicolumn{1}{c}{ Semak } \\
\hline Galinggem (Bixa orellana) & Hanjuang merah (Cordiline terminalis) \\
Bunga lampion (Brownea capitella) & Azalea (Rhododendron mucronatum) \\
Trembesi (Samanea saman) & Lantana ungu (Lantana camara) \\
Cempaka (Michelia campaka) & Akalipa hijau-putih (Acalypha godseffiana) \\
Jambu biji (Psidium guajava) & \\
Hujan mas (Cassia multijuga) & \\
Nangka (Artocarpus integra) & \\
\hline Sumber: Nasrullah et al (2000) &
\end{tabular}

Untuk polutan berupa partikel seperti debu dan timbal $(\mathrm{Pb})$ dapat digunakan tanaman-tanaman dengan kriteria seperti berdaun jarum, berbulu, bersisik, kasar, bergerigi, atau yang permukaannya lengket. Selanjutnya Gardner et al. (1991) menyatakan untuk mereduksi gas $\mathrm{CO}_{2}$, maka dapat digunakan tanaman-tanaman berdaun lebar. Semakin luas permukaan daun maka efisiensi fotosintesis akan meningkat.

Dari pernyataan mengenai kriteria di atas, maka sebaiknya digunakan vegetasi yang beragam sebab polutan bukan hanya satu jenis saja. Pemilihan lokasi juga harus disesuaikan. Misalnya untuk mengurangi dampak dari polutan $\mathrm{Pb}$ tidak harus sepanjang jalan ditanami tanaman untuk $\mathrm{Pb}$ tapi di jalur-jalur rawan. Logam $\mathrm{Pb}$ dikeluarkan mesin paling banyak ketika mobil jalan pertama kali dan ketika mobil berhenti sehingga sebaiknya tanaman $\mathrm{Pb}$ diletakkan pada daerah yang diketahui sebagai titik kemacetan, di lampu lalu lintas, dan di area parkir kendaraan.

Hal-hal lain yang dapat dilakukan yaitu Jakarta yang memiliki ruang terbangun sebesar $67 \%$, dapat memanfaatkan ruang-ruang tersebut dengan vegetasi. Pekarangan rumah dapat dipandang sebagai potensi. Pekarangan rumah, dapat dikelola dengan menanam tanaman hias. Pada dinding atau pagar dapat menggunakan green panel atau dilunakkan dengan vegetasi merambat. Pemanfaatan lahan pekarangan bukan hanya memiliki manfaat ekologis dan estetis tetapi juga bila dikelola dengan baik dapat menghasilkan manfaat ekonomi dan kesehatan. Manfaat kesehatan dapat tercipta apabila pola pemanfaatan lahan pekarangan menggunakan pendekatan urban farming dengan memproduksi tanaman yang dapat dikonsumsi. Dengan demikian pendekatan ini dapat menunjang pemenuhan gizi keluarga.

Kebutuhan $\mathrm{O}_{2}$ pada manusia bukan hanya pada siang hari tapi juga pada malam hari. Untuk itu penggunaan tanaman indoor juga direkomendasikan. Perlu diingat, pemilihan tanaman untuk indoor sebaiknya menggunakan tanaman CAM seperti anggrek (famili orchidaceae). Keunggulan tanaman CAM ini adalah mengumpulkan bahan fotosintesis pada siang hari namun berfotosintesis pada malam hari yang artinya menghasilkan $\mathrm{O}_{2}$ (Gardner et al., 1991).

Atap ruang-ruang terbangun di perkotaan seperti juga dapat dioptimalkan menjadi RTH. Arisanti et al. (2010) melaporkan beberapa tanaman yang cocok (adaptif) untuk rooftop garden yang merupakan salah satu bagian vertical greenery. Tanaman-tanaman tersebut antara lain dadap merah (Erythrina christagalli), palem ekor tupai (Wodyetia bifurcata), dan pohon kupu-kupu (Bauhinia purpurea). 
Vertical greenery juga merupakan salah satu rekomendasi yang dapat dijadikan alternatif karena memiliki fungsi ekologis dan estetis (Nurhasanah et al., 2017). Elemen perkerasan pada pembangunan di perkotaan sebaiknya tidak 100\% agar tersedia ruang untuk ditanami tanaman penutup tanah yang tahan. Fungsi lainnya juga untuk mengurangi aliran permukaan serta mengurangi heat island (Saputro et al., 2010) yang dapat mempengaruhi psikologi masyarakat (stres akibat suhu).

Hasil penelitian yang dilakukan oleh Nurhasanah et al. (2017), mengemukakan bahwa sarana dan prasarana transportasi di perkotaan dapat dimanfaatkan menjadi area hijau. Vertical greenery dapat diaplikasikan pada jembatan penyebrangan orang maupun jalan layang dengan menyediakan pocket yang dapat digunakan untuk menempatkan vegetasi. Pengaplikasian vertical greenery juga dapat diaplikasikan pada halte, stasiun, terminal, pembatas antara jalan, maupun pembatas antara trotoar.

Taman-taman yang ada di Jakarta perlu dijaga keberadaannya karena berdasarkan penelitian yang dilakukan taman kota memiliki peran yang cukup penting untuk mengurangi residu polutan (Desyana et al., 2015; Sukmawati et al., 2015). Peningkatan kualitas dan kuantitas RTH tanpa disertai dengan penataan kota tidak akan menyelesaikan masalah. Perlu adanya dukungan aspek lain seperti regulasi, partisipasi masyarakat, penyediaan moda transportasi publik ramah lingkungan, sirkulasi, dan tata ruang wilayah yang terpadu. untuk mencegah terjadinya sprawl yang nantinya akan membuat beban kota meningkat dan menciptakan lingkungan yang tidak sehat (Simonds dan Starke, 2006). Baik solusi berupa RTH maupun penempatan wilayah yang terpadu, dapat dijalankan jika adanya kerjasama dari pemerintah, masyarakat, pelaku bisnis, maupun peneliti (Newman dan Jennings, 2008) sebab masalah kesehatan kota merupakan tanggung jawab semua orang dan hasilnya untuk semua orang.

\section{Simpulan}

RTH memiliki peran dalam menyelesaikan masalah kesehatan perkotaan. Keberadaan RTH dapat mereduksi resiko penyakit yang diakibatkan oleh polutan. Berdasarkan proyeksi kebutuhan oksigen dan jumlah kendaraan di Jakarta dari tahun ke tahun terus meningkat seiring dengan pertambahan jumlah penduduk. Dengan peningkatan tersebut, kebutuhan luas RTH juga meningkat. Proyeksi kebutuhan RTH Jakarta pada tahun 2017 sebesar 2.915.927,743 m² (291,592 ha). Penambahan kebutuhan ini berkebalikan dengan realita yang ada karena luas area hijau di Jakarta cenderung terus menyusut akibat pembangunan. Berbagai solusi yang dapat digunakan untuk meningkatkan kualitas kesehatan masyarakat perkotaan dengan keterbatasan luasan RTH antara lain penggunaan vegetasi yang efektif mereduksi polutan, pemanfaatan pekarangan, pengamplikasian vertical greenery, pemanfaatan indoor garden, dan mempertahankan keberadaan taman kota. 


\section{Daftar Pustaka}

Arisanti, A., A. Munandar., dan T. Prawitasari. 2010. Adaptasi Anatomis Pohon pada Roof Garden (Studi Kasus: Kondominium Taman Anggrek, Jakarta). Jurnal Lanskap Indonesia, 2(2):69-75.

Desyana, R.D., E.J. Muakhor, dan P.T. Putra. 2015. Potential of City Parks in Reducing Urban Pollutants. In The 5th International Conference of Jabodetabek Study Forum: Sustainable Megacities: Vulnerability, Diversity and Livability. Edited by: Rustiadi, E., S. Muramatsu, A.F.M. Zain, and J.T. Hidajat. Crestpen Press. Bogor.

Efendi, Y.H., Briawan, D., dan Ekayanti, I. 2009. Bioetika dan Kesehatan Masyarakat. Fakultas Ekologi Manusia IPB, Bogor.

Gardner, F.P., R.B. Pearce., dan R.L. Mitchel. 1991. Fisiologi Tanaman Budidaya. (diterjemahkan dari : Physiology of Crop Plants, translator: H. Susilo). Penerbit Universitas Indonesia, Jakarta.

Genc, S., Z. Zadeoglulari, S.H. Fuss, dan K. Genc. 2011. The Adverse Effects of Air Pollution on The Nervous System. Journal of Toxicology, 2012(2012):1-23.

Hoek, G., R.M. Krishnan, R. Beelen, A. Peters, B. Ostro, B. Brunekreef, dan J.D. Kaufman. 2013. Long-term Air Pollution Exposure and Cardio-respiratory Mortality: A Review. Journal of Environmental Health 12(43):1-16.

Intelresos. 2007. Fakta tentang gangguan jiwa. Integrasi Layanan Rehabilitasi Sosial. Available online at http://intelresos.kemsos.go.id/?module=Program+Gsp\&view=fakta (accessed 2 August 2017).

Joga, N. dan I. Ismaun. 2011. RTH 30\% Resolusi (Kota) Hijau. PT. Gramedia Pustaka Utama, Jakarta.

Lin, Y., L. Zhou, J. Xu, Z. Luo, H. Kan, J. Zhang, C. Yan, dan J. Zhang. The Impacts of Air Pollution on Maternal Stress during Pregnancy. 2017. Scientific Reports (7):40956:1-11.

Liu, Y., S. Yan, K. Poh, S. Liu, E. Iyioriobhe, dan D.A. Sterling. 2016a. Impact of Air Quality Guidelines on COPD Sufferers. International Journal of COPD, 11(2016):839-872.

Liu, R., M.T. Young, J.C. Chen, J.D. Kaufman, dan H. Chen. 2016b. Ambient Air Pollution Exposures and Risk of Parkinson Disease. Environ Health Perspect, 124(11):17591765.

McHarg, I.L. 1971. Design with Nature. Natural History Press Doubleday \& Company Inc, New York.

Muis, BA. 2005. Analisis Kebutuhan Ruang Terbuka Hijau Berdasarkan Kebutuhan Oksigen dan Air di Koa Depok Propinsi Jawa Barat [tesis]. Institut Pertanian Bogor, Bogor

Nasrullah, N., S. Gandanegara., H. Suharsono., M. Wungkar,. dan A. Gunawan. 2000. Pengukuran Serapan Polutan gas $\mathrm{NO}_{2}$ pada tanaman tipe pohon, semak, dan penutup tanah dengan menggunakan gas $\mathrm{NO}_{2}$ bertanda $15 \mathrm{~N}$. In Risalah Pertemuan Ilmiah Penelitian dan Pengembangan Teknologi Isotop dan Radiasi. Edited by: 
Badan Tenaga Nuklir Nasional Puslitbang Teknologi Isotop dan Radiasi. P3TIRBATAN, Jakarta.

Newman, P. dan I. Jennings. 2008. Cities as Sustainable Ecosystems Principles and Practice. Island Press, Washington.

Noorastuti, P.T. dan N.T. Kurniawan. 2009. Orang gila terbanyak di Indonesia ada di Jakarta. Viva. Availavle online at http://metro.news.viva.co.id/news/read/50421orang_gila_terbanyak_ada_di_jakarta (accessed 9 Januari 2013].

Nurhasanah, F., I.U. Utami, dan R.M. Syahadat. 2017. Vertical Greenery pada Sarana dan Prasarana Transportasi Publik untuk Mendukung Kota Hijau. Vitruvian Jurnal Arsitektur, Bangunan, \& Lingkungan, 6(3):101-108.

Panjaitan, T.P.M., B. Pramudya., Manuwoto., dan I.F.P. Poerwo. 2011. Pengelolaan Pencemaran Udara Akibat Transportasi di Kawasan Perumahan di Pinggiran Metropolitan. Jurnal Sabua, 3(1):1-8.

Parjiyono, Y. 2010. Masalah sosial: razia terus dilakukan, masih saja ada orang gila. Surakarta Online. Available online at http://www.suarakaryaonline.com/news.html?id=265333 (accessed 9 January 2013).

Saputro, T.H., I.S. Fatimah, dan B. Sulityantara. 2010. Studi Pengaruh Area Perkerasan terhadap Perubahan Suhu Udara (Studi Kasus Area Parkir Plaza Senayan, Sarinah Thamrin, dan Stasiun Gambir). Jurnal Lanskap Indonesia, 2(2):77-82.

Sasmita, I dan K.R. Ucu. 2012. Kualitas udara buruk, 'sejuta' penyakit ancam Jakarta. Republika. Available online at http://www.republika.co.id/berita/nasional/jabodetabek-nasional/12/10/21/mc8otzkualitas-udara-buruk-sejuta-penyakit-ancam-warga-jakarta (accessed 9 January 2013).

Segalowitz, S.J. 2008. Public Health, Brain Health, and The Dangers of Air Pollution for Neural Development. Brain Cogn, 68(2):115-116.

Simonds, J.O. dan B.W. Starke. 2006. Landscape Architecture. McGraw-Hill Companies, Inc, New York.

Sukmawati, T., H. Fitrihidajati, dan N.K. Indah. Penyerapan Karbondioksida pada Hutan Kota di Surabaya. LenteraBio, 4(1):108-111.

Sunyer, J. M. Esnaola, M. Alvarez-Pedrerol, J. Forns, I. Rivas1, M. López-Vicente, E. Suades-González, M. Foraster, R. Garcia-Esteban, X. Basagaña, M. Viana, M. Cirach, T. Moreno, A. Alastuey, N. Sebastian-Galles, M. Nieuwenhuijsen, dan X. Querol. 2015. Association between Traffic-related Air Pollution in Schools and Cognitive Development in Primary School Children: A Prospective Cohort Study. PLoS Med, 12(3):1-24. 